\title{
Investigating Learning Strategies for Vocabulary Development: A Comparative Study of Two Universities of Quetta, Pakistan
}

\author{
Irum Fatima (Corresponding author) \\ Department of English, Sardar Bahadur Khan Women's University, Barori Road, Quetta, Pakistan \\ E-mail: fatimairum01@gmail.com \\ Zahid Hussain Pathan \\ English Language Center, University of Balochistan, Sariyab Road, Quetta, Pakistan \\ E-mail: pathanzahid82@yahoo.com
}

Doi:10.7575/aiac.alls.v.7n.2p.7

URL: http://dx.doi.org/10.7575/aiac.alls.v.7n.2p.7
Received: 27/10/2015

Accepted: 24/12/2015

\begin{abstract}
The primary purpose of this research is to investigate the vocabulary learning strategies employed by the undergraduate students of Sardar Bahadur Khan Women's University (SBKWU) and University of Balochistan (UOB), Quetta, Pakistan. A quantitative design was employed in this study to answer the two research questions of the present study. The quantitative data was obtained from the responses of 180 undergraduates in a questionnaire adapted from the study by Noor and Amir (2009) on vocabulary learning strategies proposed by Gu and Johnson (1996). The questionnaire comprised of 45 close-ended items on four broad vocabulary learning strategies, metacognitive regulation strategy, cognitive strategy, memory strategy, and activation strategy. Descriptive statistics was run in SPSS to obtain the results. The independent-samples t-test was run to test for statistically significant differences if any in the use of vocabulary learning strategies across the undergraduates of two universities. However, cognitive regulation strategy, and activation strategy emerged as the most influential source of learning new English words. The findings also revealed that there were no statistically significant differences found in practicing vocabulary learning strategies between undergraduates of SBKWU and UOB. The findings of the study have implications on enhancing teaching and learning by acquainting students with vocabulary learning strategies that can enhance their vocabulary in English language and can result to boost up their proficiency in this language.
\end{abstract}

Keywords: Vocabulary development, learning strategies, gender difference

\section{Introduction}

Nowadays, English language has become the most dominant language among all the languages of the world and is being learnt, read and spoken widely throughout the world (Jenkin, 2006; Parkir, 2000; Kachru \& Nelson, 1996). To learn a foreign or second language effectively, lexical knowledge plays a vital role. Vocabulary acquisition makes second language learners (L2) adept in accurate meaning, spelling and derivations (Fan, 2003). Wilkins (1972) asserted that "without grammar very little can be conveyed, without vocabulary nothing can be conveyed" (p. 111). McCarthy and Carter (2001) stated that the biggest problem for most of the learners is vocabulary and it is considered as the major part of the meaning of any language.

Vocabulary acquisition can enable L2 learners to be proficient in the target language (Zareva et al, 2005). A number of researchers have agreed to acquaint students to learn vocabulary learning strategies in order to have command over all the skills of the target language (Read, 2000; Schmitt, 2000; Cunningworth, 1995). In the similar vein, Sokmen (1997. $\mathrm{p}, 14)$ states that "vocabulary learning strategies are "a powerful approach", which can be based on sensitization to the systems of vocabulary learning, encouragement of sound dictionary skills and reflection of effective learning techniques."

To learn a foreign or a second language effectively, it is a vocabulary acquisition that manipulates all the four skills of a language; speaking, writing, listening and reading that pave a way for an effective communication. Due to the importance of vocabulary, vocabulary acquisition is receiving its attention in research and second language pedagogy. The issues pertinent to the vocabulary learning strategies employed by students and how vocabulary can be taught need to be seriously addressed in order to enable L2 learners to command over the target language (Nassaji, 2003; Catalan, 2003; Hatch \&Brown, 1995).

Despite the key role of vocabulary in the academic achievement of L2 learner, vocabulary acquisition is given a little attention in the curriculum designed in the Asian universities (Fan, 2003). Moreover, teaching of vocabulary learning 
strategies is also given least attention in EFL classrooms (Catalan, 2003). Students are only acquainted with word meaning when they come across difficult words and phrases. As vocabulary knowledge, which is a key to learn the target language effectively, is dependent on vocabulary learning strategies, ineffective learning strategies create an effective vocabulary knowledge that causes students' failure in a foreign or second language acquisition (Fan, 2003).

\section{Importance of the research}

Words form the foundation upon which a language is built. Learning lexical items therefore leads to the knowledge of a specific language. Indeed, language students face challenges with using vocabulary despite progressing from initial stage of learning a foreign language to an advanced stage (Lee, 2011; Smith et al., 2013). Nation (2001) states that learning vocabulary has significant importance in achieving proficiency in the target language and there is a dire need to explore the research pertinent to VLS in different social contexts. Once the second/foreign language learners are imparted with the effective language learning strategies, learners can learn the target languages with an acute ease. In the same vein, Nunan (1999) asserted that successful learners are mostly acquainted with variety of language learning strategies that pave a way for them to grasp the structure of the target language effectively whereas less effective learners employ scanty of strategies that results ineffective language learning. It is, therefore, very important to investigate vocabulary learning strategies (VLS) related matters in different social contexts so as to gain a better understanding of this issue.

The study conducted by Khatib et al., (2011) aimed at examining preferred vocabulary learning strategies employed by upper-intermediate EFL learners in Iran. Vocabulary Learning Strategies Inventory questionnaire was administered among 480 students. The data was analysed in SPSS using multiple regression analysis tests. The findings revealed that self-motivation for memorising words of the target language, word organization, and authentic language use emerged as the most influential vocabulary learning strategies practiced by the EFL learners.

Gu and Johnson (1996) carried out the study in which 850 second year Chinese students were administered a VLS questionnaire, proficiency tests and vocabulary size tests. The questionnaire was based on four broad strategies: Metacognitive regulation includes (self-initiation strategies, selective attention strategy); Cognitive strategy that includes guessing strategies, dictionary Strategies, note-taking strategies; Memory strategies; and Activation strategies. The findings revealed that self-initiation and selective attention strategies emerged as the most influential predictors for EFL learners.

In Japan, Schmitt (1997) carried out research among 600 students belonging to low, medium and high proficiency level. This quantitative research study administered a questionnaire comprising of 40 strategies. The findings showed that the use of bilingual dictionary (95\%) emanated as the most frequent vocabulary learning strategy employed by the Japanese students followed by the strategy asking teachers for the synonyms of the words $(86 \%)$ as the second most practiced VLS. Whereas, skipping difficult words (16\%) were the least practiced VLS among these students.

Keeping in view the importance of the vocabulary in second/foreign language learning, this study investigates which of the four vocabulary learning strategies are preferably employed by the undergraduate students of University of Balochistan, Quetta (UOB) and SBK Women's University, Quetta (SBKWU) proposed by Gu and Johnson (1996). The strategies are: 1). Metacognitive strategy includes (self-initiation strategies, selective attention strategy), 2). Cognitive strategy includes (guessing strategies, dictionary strategies, and note-taking strategies, 3) Memory strategy, 4) Activation strategy.

\section{Research Objectives}

- To identify vocabulary learning strategies employed by undergraduates of Sardar Bahadur Khan Women's University (SBKWU) and University of Balochistan (UOB), Pakistan.

- To determine whether there is any statistical significant difference in employing vocabulary learning strategies between undergraduates of SBKWU and UOB, Pakistan.

\section{Research Questions}

- What vocabulary learning strategies are employed by undergraduates of Sardar Bahadur Khan Women's University (SBKWU) and University of Balochistan (UOB), Pakistan?

- Is there any statistical significant difference in employing vocabulary learning strategies between undergraduates of SBKWU and UOB, Pakistan?

\section{Research Design}

This study employed quantitative research design. Gu and Johnson (1996) proposed four vocabulary learning strategies which is used as a theoretical framework and a guide for this study. All these four strategies are summarized in the following Table1: 
Table 1. Vocabulary Learning Strategies (VLS) Taxonomy Proposed by Gu and Johnson (1996)

\begin{tabular}{|c|c|c|c|}
\hline Metacognitive Strategies & Cognitive Strategies & Memory Strategies & $\begin{array}{l}\text { Activation } \\
\text { Strategies }\end{array}$ \\
\hline $\begin{array}{l}\text { *Selective Attention: } \\
\text { Identifying essential } \\
\text { meaning of the words } \\
\text { *Self-initiation: Using a } \\
\text { variety of means to make } \\
\text { the meaning of the words } \\
\text { clear }\end{array}$ & $\begin{array}{l}\text { *Guessing: Activation } \\
\text { background } \\
\text { knowledge, using } \\
\text { linguistic items. } \\
\text { *Use of dictionaries } \\
\text { *Note-taking }\end{array}$ & $\begin{array}{l}\text { *Rehearsal: Words } \\
\text { lists, repetition, etc. } \\
\text { "Encoding: } \\
\text { Association, } \\
\text { (imagery, visual } \\
\text { auditory, etc.) }\end{array}$ & $\begin{array}{l}\text { *Using new } \\
\text { words in } \\
\text { different } \\
\text { contexts }\end{array}$ \\
\hline
\end{tabular}

This study included 180 (80 from UOB and 100 from SBK Women's university) undergraduate students who were randomly selected from different departments of the university that offer undergraduate programs. At University of Balochistan (UOB) and Sardar Bahadur Khan Women's University (SBKWU), all the undergraduate students are offered Functional English Language (FEL) as a compulsory subject. This subject covers all the four skills of English language: Listening, Speaking, Reading and Writing. Since, students are required to pass this course and they put their endless efforts to qualify this exam. Therefore, they were in better position to give the accurate data that would likely to reflect upon the vocabulary learning strategies they employ while learning new English words. The students were aged between 18 to 25 .

A questionnaire designed by Noor and Amir (2009) on vocabulary learning strategies proposed by Gu and Johnson (1996) was administered in this study. The adapted version of the questionnaire for this study consisted of 45 items based on five-point Likert scale ranging from Strongly Agree (5) to Strongly Disagree (1) that investigated VLS on four constructs as cited in the Table 1 above.

\subsection{Pilot Study}

A pilot study was carried out with 30 undergraduates (15 from UOB and 15 from SBKWU) studying in the second semester at the University of Balochistan, and Sardar Bahadur Khan Women's University Quetta, Pakistan. To check the validity of the questionnaire, focus group discussion was done and items were revised accordingly. To check the reliability of the questionnaire, Item Reliability Analysis was run for all the 45 items in the questionnaire and the value for the "Cronbach's alpha reliability test" was 0.851 .

\subsection{Data Collection Procedure}

During data collection, the undergraduates were given instructions in both Urdu and English language to help them answer the questionnaire with an ease. Moreover, the respondents were given 30 to 45 minutes to respond to the questionnaire.

\subsection{Data Analysis}

In order to answer the first research question of the study, descriptive statistics was performed in the SPSS (version, 21) to determine the preferred vocabulary learning strategies employed by the undergraduates of two universities of Pakistan. To answer the second research question of the study, inferential statistics was performed in which Independent-Samples t-test was run in SPSS to determine whether there were any statistically significant differences in practicing vocabulary learning strategies between undergraduates of two universities of Pakistan. Pallant (2013) asserts that independent-Samples t-test measures the difference between two groups on various constructs.

\section{Findings And Discussion}

\subsection{Findings}

To answer the first research question of the study, descriptive statistics against each construct in the questionnaire is summarised in the following Table 2:

Table 2. Descriptive Statistics for SBKWU and UOB Students on Practice of VLS

\begin{tabular}{llll}
\hline VLS & Students & Mean & SD \\
\hline Metacognitive Strategy & SBKWU & 1.98 & 1.17 \\
& UOB & 1.93 & 1.09 \\
Cognitive Strategy & SBKWU & 3.21 & 1.30 \\
& UOB & 2.57 & 1.43 \\
Memory Strategy & SBKWU & & 1.23 \\
& UOB & 2.23 & 1.28 \\
Activation Strategy & SBKWU & 2.34 & 1.24 \\
& UOB & 2.39 & 1.40 \\
\hline
\end{tabular}


Table 2, above shows that out of the four constructs clustered on vocabulary learning strategies, the mean scores of SBKWU students were greater than those of UOB students on use of cognitive strategy in learning new English words. On the contrary, UOB students' mean scores were greater than SBKWU students on the use of activation strategy. The findings imply that the students of SBK Women's University profusely used cognitive strategy that includes note taking strategy, dictionary strategy for looking up the meaning of new word, and guessing strategy for learning new words by employing the knowledge of word structure i.e. prefix, and suffix and parts of the speech of the words. Whereas, the students of university of Balochistan (UOB) largely employ activation strategy that includes use of new words to make their passive vocabulary active by using it in both reading and writing. However, the students of the both universities also practice both metacognitive strategy and memory strategy to learn new English words.

To answer the second research question of the study, inferential statistics was performed in which Independent-Samples T-test was run in SPSS to determine whether there were any statistical significant differences in practicing vocabulary learning strategies between undergraduates of two universities of Pakistan.

Table 3. Indpendent-Samples t-test Results for the Undergrduates of SBKWU and UOB

\begin{tabular}{lcccccccc}
\hline VLS & \multicolumn{2}{c}{ SBKWU } & \multicolumn{2}{c}{ UOB } & & \\
\hline & Mean & SD & Mean & SD & t & df & p \\
Metacognitive Strategy & 2.30 & 1.173 & 2.14 & 1.14 & .644 & 65 & .522 \\
Cognitive Strategy & 2.20 & 1.030 & 2.07 & 1.08 & .634 & 65 & .528 \\
Memory Strategy & 1.92 & .857 & 1.89 & .916 & .612 & 65 & .901 \\
Activation Strategy & 2.5897 & 1.33215 & 2.58 & 1.60 & .731 & 65 & .467 \\
\end{tabular}

Difference is significant at $\mathrm{p}<.05$

In the Table 3 above, the findings reveal that there was no statistically significant difference at the p<.05 level in employing VLS by the undergraduates of SBKWU and UOB. According to Pallant (2013) the difference between groups can be determined at the point when the significance value of t-test is less than $\mathrm{p}<.050$.

\subsection{Discussions}

Based on the findings in section 6.1 above, cognitive strategies emerged as the leading strategies for undergraduates of SBK Women's University. It was reported that the undergraduates of SBKWU employ guessing strategy to learn the meaning of new words. These participants also reported that they use the knowledge of the topic and parts of the speech of the words to guess the appropriate meaning of the words. These findings are in line with the findings of the study by Dóczi, (2011); Gu and Johnson (1996), and Takač (2008) where they found cognitive strategies as the one of the most practiced strategies among the English language learners to learn new English words. The use of dictionary strategies also emerged as the potential strategy to learn new English words among the undergraduates of SBK Women's University. The research participants reported that they use dictionary strategies profusely to look up into the appropriate usage of English words. Additionally, they also use bilingual dictionary to know the meaning of the English words into Urdu language. Schmitt (2000) also stated that use of the bilingual dictionary facilitates L2 learners to command over the vocabulary of the target language. In the Similar Vein, Elman (2004) "the knowledge of the word is usually thought to reside in the mental lexicon, a kind of dictionary that contains information regarding a word's knowledge". Majority of the research participants from SBK Women's University also reported that they also abundantly use note taking strategies to learn new English words. They reported that they maintain the list of the words having both synonyms and antonyms to gain the deep knowledge of the words. However, majority of the students of the University Balochistan (UOB) preferred using activation strategy to enhance their vocabulary in the target language. They further reported that noting the example of the words used in the particular context enables them to remember and keep their vocabulary active by using them in speaking and writing skills in an academic setting. This is the observable technique that students use to enhance their vocabulary in learning vocabulary in the target language. This empirical evidence reveals that the students of the both the universities are well aware about the crucial importance of the vocabulary in learning the target language. This importance of VLS in English language might have emerged among these students owing to the fact that it is the official language of Pakistan and it is the key to get employed on the good posts in the Pakistani context.

The result of the independent-samples t-test revealed that there was no statistically significant difference in the use of VLS between the undergraduates of two universities. This finding was contrary to the findings of the studies by Jiménez (2003) and Grace (2000) in which they concluded that female learners used more VLS than male learners. However, this finding is similar to the findings of the study by Arjomand and Sharififar (2011). This finding might have emanated because both the universities are situated in the same city Quetta, having similar learning and cultural environment. The students of the both universities equally employed VLS strategies as proposed by Gu and Johnson (1996). 


\section{Conclusion}

Over the past few decades, many researches have pointed out the importance of vocabulary learning strategies as key to enhance a foreign or second language acquisition (Nemati, 2013; Yang, 2007). The findings suggest that activation strategy, memorization strategy; metacognition regulation strategy and cognitive strategy like guessing word meaning by the context and parts of the speech of the words; note taking strategies and dictionary strategies emerged as the most practiced vocabulary learning strategies by the undergraduates of both SBK Women's University and University of Balochistan. These finding support the findings of studies by Fan (2003); Gu, (2003); Gu and Johnson, (1996); Nassaji, (2003); Khaldieh, (2000). The findings depict that vocabulary learning strategies as cited by undergraduates of SBKWU and UOB were similar in application of independent-samples t-test. However, the difference was only in mean scores where the order of use of vocabulary learning strategies was different.

\subsection{Limitations of the Study}

The first limitation of this study is that, this study only surveyed the undergraduate students of SBK Women's University and University of Balochistan which is situated in same city, Quetta in one of the five provinces of Pakistan. Therefore, the results of this study cannot be generalized to all undergraduates in other cities of Pakistan. The second limitation is that this study only used questionnaires to collect the quantitative data. Therefore, some students may not have answered the questionnaires sincerely. Triangulation of the data was not performed to confirm the findings through the use of different data collection methods such as interviews and vocabulary proficiency test which may provide in-depth insights into feedback of students on the use of vocabulary learning strategies (VLS). The third limitation of this study is that the questionnaire was not translated into the mother tongue of students, that is, the Urdu language. By translating the items, students may further understand all the items in the questionnaire without having to depend on the explanation provided by the researcher prior to answering the questionnaire.

\subsection{Implications of Study}

Vocabulary learning strategies in learning new words in the target language has been the center of discussion among L2 researchers and instructors and it is considered as a key source to learn a second or foreign language effectively. Similarly, how to increase the vocabulary of the students in the target language, as Wilkins (1972) stated that "without grammar very little can be conveyed, without vocabulary nothing can be conveyed" (p. 111), therefore, this study has familiarized English language teachers with the better understanding of vocabulary learning strategies that students employ to enhance their vocabulary in the target language. Therefore, Pakistani, English language teachers can incorporate these VLS into their teachings to help their students to improve their vocabulary in English language. Finally, the findings of this study are likely to benefit those researchers in Pakistan who are currently working on second language acquisition/learning with focus on vocabulary learning strategies. They can use this study as one of the examples in the Pakistani context that what vocabulary learning strategies are employed by the undergraduates of two universities of Pakistan. This study also contributes to the existing literature on vocabulary learning strategies in general and particular in Pakistani context.

\subsection{Suggestions for Future Research}

This study investigated the vocabulary learning strategies employed undergraduates of two universities of Quetta, Pakistan, therefore, some suggestions are provided for future research. Since, this study focused on two public universities situated in Pakistan, therefore further research should concentrate on students of public and private universities in Pakistan so that a comparison of vocabulary learning strategies can be made and it can generate significantly different results. Secondly, interviews can be considered for future research to gain deep insights into the beliefs of students towards vocabulary learning strategies (VLS). Since a questionnaire may not include all the possible VLS, interviews may be used to serve as triangulation or to complement the findings of the study. Thirdly, future researchers can also consider the experimental study to explore the effectiveness of VLS as proposed by Gu and Johnson (1996).

\section{References}

Arjomand, M. \& Sharififar, M. (2011). The most and least frequently used vocabulary learning strategies among Iranian EFL Freshman Students and Its Relationship to gender. Iranian EFL Journal, 7(1), 90-100.

Catalan, R. (2003). Sex differences in L2 vocabulary learning strategies. Applied Linguistics, 13(1), 54-77.

Cunningsworth, A. (1995). Choosing your course book. Oxford: Heinemann

Dóczi, B. (2011). Comparing the vocabulary learning strategies of high school and university students: A pilot study. WoPaLP, 5, 138-158.

Elman, J. L. (2004). An alternative view of the mental lexicon. Trends in cognitive sciences, 8(7), 301-306.

Fan, Y. M. (2003). Frequency of use, perceived usefulness, and actual usefulness of second language vocabulary strategies: A study of Hong Kong learners. The Modern Language Journal, 87(2), 222-241

Grace, C. (2000). Gender differences: Vocabulary retention and access to translations for beginning language learners in CALL. The Modern Language Journal, 84, 214-224. 
Ghazal, L. (2007). Learning vocabulary in EFL contexts through vocabulary learning strategies. Novitas-Royal, 1(2), 84-91.

Gu, Y., \& Johnson, R. K. (1996). Vocabulary learning strategies and language learning outcomes. Language Learning, 46, 643-697.

Hatch, E., \& Brown, C. (1995). Vocabulary, semantics, and language education. Cambrideg: Cambridge University Press

Jenkins, J. (2006). Current perspectives on teaching World Englishes and English as a lingua franca. TESOL Quarterly, 40(1), 157-181.

Jiménez, R. M. (2003). Sex differences in L2 vocabulary learning strategies. International Journal of Applied Linguistics, 13, 1, 54-77.

Kachru, B.B., \& Nelson, C.L. (1996). World Englishes. In S.L. MaKay \& N.H.

Khaldieh, S. A. (2000). Learning strategies and writing process of proficient vs. less proficient learners of Arabic. Foreign Language Annals, 33(5), 522-533.

Khatib, M., Hassanzadeh, M., \& Rezaei, S. (2011). Vocabulary learning strategies of Iranian upper-intermediate EFL learners. International Education Studies, 4(2), p144.

Lee, J. (2011). Size matters: Early vocabulary as a predictor of language and literacy competence. Applied Psycholinguistics, 32(01), 69-92.

Nassaji, H. (2003). L2 vocabulary learning from context: Strategies, knowledge sources, and their relationship with success in L2 lexical inferencing. Tesol Quarterly, 37(4), 645-670.

Nation, I. S. (2001). Learning vocabulary in another language: Ernst Klett Sprachen.

Nemati, A. (2013). Vocabulary learning strategies: A short way to long term retention. Linguistics and Literature Studies, 1(1), 8-18.

Noor, M. N., \& Amir, Z. (2009).Exploring the vocabulary learning strategies of EFL learners. Language and Culture: Creating and Fostering Global Communities. 7th International Confronce by the School of Studies and Lingustics Faculty of Social Sciences and Humanities, 313-327.

Nunan, D. (1999). Second language teaching \& learning. Heinle \& Heinle Publishers, 7625 Empire Dr., Florence, KY 41042-2978.

Pakir, A. (2000). The Development of English as a" Glocal" Language: New Concerns in the Old Saga of Language Teaching. Anthology Series-Seameo Regional Language Center, 14-31.

Pallant, J. (2013). SPSS survival manual. McGraw-Hill Education (UK).

Read, R. (2000). Assessing vocabulary. Cambridge University Press.

Schmitt, N. (2000). Vocabulary in language teaching. New York: Cambridge University Press.

Sokmen, A. (1997). Current trends in teaching second language vocabulary. Cambridge: Cambridge University Press.

Smith, B. R., Spooner, F., Jimenez, B. A., \& Browder, D. (2013). Using an Early Science Curriculum to Teach Science Vocabulary and Concepts to Students with Severe Developmental Disabilities. Education and Treatment of Children, 36(1), 1-31.

Takač, V. P. (2008). Vocabulary learning strategies and second language acquisition. Clevedon,

UK: Multilingual Matters.

Wilkins, D. (1972). Linguistics in language teaching. London, UK: Arnold.

Yang, M. (2007). Language learning strategies for junior college students in Taiwan: Investigating ethnicity and proficiency. EFL Asian Journal, 9(2), 35-57

Zareva, A., Schwanenflugel, P. \& Nikolova, Y. (2005). Relationship between lexical competence and language proficiency: Variable sensitivity. Studies in Second Language Acquisition, 27, 567-595. 